\title{
Estabilidad ocupacional reforzada en Colombia: Una mirada crítica desde la jurisprudencia ${ }^{1}$
}

\section{Strengthened occupational stability in Colombia: a critical view from jurisprudence}

DOI: https://doi.org/10.17981/juridcuc.15.1.2019.02

Fecha de Recepción: 09/febrero/2019 Fecha de Aceptación: 18/abril/2019

\author{
Darwin Eliecer Solano Bent, iD \\ Universidad de la Costa (Colombia) \\ dsolano1@cuc.edu.co
}

Para citar este artículo:

Solano, E. (2019). Estabilidad ocupacional reforzada en colombia: una mirada crítica desde la jurisprudencia. JURÍDICAS CUC, 15(1). 47-68. DOI: http://dx.doi.org/10.17981/ juridcuc.15.1.2019.02

\section{Resumen}

El derecho laboral está caracterizado por desarrollar dentro de sus principios, la igualdad y la justicia como elementos propositivos basados en la argumentación de las normas laborales que constituyen fundamentos para promover la eficiencia productiva y la justicia social. En este orden de ideas, el objetivo del presente artículo de reflexión es analizar, bajo una metodología cualitativa con enfoque documental, los diferentes pronunciamientos dados por los Altos Tribunales colombianos frente a algunos eventos en donde a los trabajadores se les brindó estabilidad reforzada y las consecuencias de no cumplir con los procedimientos establecidos para desvincular a estos de sus trabajos. $\mathrm{Pa}$ ra concluir con la posibilidad de evidenciar a partir de las sentencias analizadas sobre estabilidad laboral reforzada, el garantismo brindado por esta vía a los diferentes trabajadores, lo cual implica para los empleadores el verse obligados a cumplir con unos formalismos particulares al momento de terminar relaciones laborales con los sujetos de especial protección.

Palabras clave: Disminuido físico; estabilidad laboral; estabilidad ocupacional; jurisprudencia

\begin{abstract}
Labor law is characterized by the development, within its principles, of equality and justice as propositional elements based on the argumentation of Labor standards that constitute the basis for promoting productive efficiency and social justice. In this order of ideas, the objective of this article is to analyze, under a qualitative methodology with a documentary focus, the different pronouncements given by the Colombian High Courts in front of some events in which the workers were offered reinforced stability and the consequences of not complying with the procedures established to disassociate them from their work. To conclude with the possibility of demonstrating, based on the judgments analyzed, the reinforced job stability, the guarantee offered in this way to the different workers, which implies that employers are obliged to comply with particular formalities at the time of terminating labor relations with subjects of special protection.

Keywords: Physical handicap; labor stability; occupational stability; jurisprudence
\end{abstract}

${ }^{1}$ Artículo de reflexión producto de investigaciones interdisciplinarias (trabajos de grado, proyectos) de los autores, en la línea de investigación Convivencia, Paz y Justicia, sublínea Relaciones Individuo-Estado, Democracia y Ciudadanía.

The author; licensee Universidad de la Costa - CUC. 


\section{Introducción}

Con la expedición de la Ley 361 (1997) en Colombia, se establecieron mecanismos de integración social de las personas con limitación y los cuales fueron calificados para el 2001 como: moderado el que incluye una pérdida de la capacidad laboral de entre el $15 \%$ y el $25 \%$; como severo en el que va desde el $25 \%$ hasta el $50 \%$ de la perdida de la capacidad laboral; y el profundo en el que la pérdida es superior al 50\% (Decreto 2463, 2001). Teniendo esto como punto de partida, los sujetos que se encontraban con estas pérdidas de capacidad laboral se volvían sujetos de especial protección para el legislador, en mayor o menor proporción dependiendo a su discapacidad, pero todos ellos protegidos.

La intención de esta ley era garantizar el cumplimiento de los principios consagrados en los artículos 13, 47, 54 y 68 de la Constitución Política (1991), donde se reconoce la dignidad propia de las personas con limitación en sus derechos fundamentales, económicos, sociales y culturales, para su completa realización personal y su total integración social, y a las personas con limitaciones severas y profundas la asistencia y protección necesarias (Ley 361, 1997, p. 1). Y además, asegurar la no discriminación sobre ningún habitante del territorio nacional colombiano por condiciones "personales, económicas, físicas, fisiológicas, síquicas, sensoriales y sociales" (Ley 361, 1997, p. 1). Lo anterior, en concordancia con el derecho al trabajo como derecho fundamental, reconocido en varios instrumentos legales internacionales, el cual es esencial para lograr otros derechos humanos y forma parte inseparable e inherente de la dignidad humana, y al mismo tiempo, también permite al individuo y su familia ganar su manutención. Porque, en la medida que el trabajo se elige o acepta libremente, fomenta el desarrollo personal y social (Rojas, 2016).

Es así, como el Estado colombiano, incursiona en este momento histórico en regular la estabilidad laboral reforzada (posteriormente denominada estabilidad ocupacional) no solo por un 
mandato constitucional del Estado, sino haciendo extensivo el bloque constitucional en el que se equipara a nuestra carta magna con instrumentos internacionales tales como la Declaración de los Derechos Humanos (Resolución 217A, 1948), la Declaración de los Derechos del Deficiente Mental (Resolución 2856, 1971), la Declaración de los Derechos de los impedidos (Resolución 3447, 1975), la declaración concerniente al Programa de Acción Mundial para los Impedidos (Resolución 3828, 1983) proclamadas por la Asamblea General de las Naciones Unidas; al convenio sobre personas invalidas (Convenio C159, 1983), la recomendación sobre personas invalidas (Recomendación R168, 1983) de la Organización Internacional del Trabajo-OIT, y la Declaración de SundBerg de la Organización de las Naciones Unidas para la Educación, la Ciencia y la Cultura (UNESCO 1981), entre otros (Asociación Nacional de Empresarios de Colombia-ANDI, 2017).

Con la expedición de la Ley 361 (1997), queda en firme en Colombia, el primer antecedente legislativo, en un país que no se caracteriza por brindar estabilidad laboral a las personas con disminución física, con el poder de exigir el cumplimiento de una Ley que garantiza sus derechos. Expedidas así, las primeras normas alusivas que tienen como objeto a los sujetos de especial protección, encontrando aun así, la existencia de algunas situaciones en las que se encontraban inmersos estos mismos sujetos y en las cuales la aplicación de la ley no era lo suficientemente clara. En ese afán de llenar los vacíos existentes, las Altas Cortes intentaron llenarlos por la vía jurisprudencial, llevando a cuestionar en el siguiente análisis hasta qué punto esas doctrinas de los Altos Tribunales han servido para solucionar problemas de interpretación de la Ley en situaciones concretas.

A partir de lo anteriormente expuesto, el presente artículo de reflexión analiza los diferentes planteamientos desarrollados en 10 años por el legislador y las altas Cortes colombianas, respecto a la hoy denominada estabilidad ocupacional reforzada. Por lo cual, en primera medida se analizan los principales 
planteamientos de sentencias de la Corte Constitucional abordando el estado de la estabilidad laboral reforzada, el estado de debilidad manifiesto y las consecuencias de no realizar los procedimientos de los trabajadores con limitación sin acotar los protocolos establecidos por el Ministerio del Trabajo. Asimismo, se abordan temáticas como la protección del trabajador en condición de discapacidad, la protección reforzada de la mujer embarazada o en lactancia y los procesos para la terminación de estos.

\section{Discusión}

La estabilidad laboral, es definida como aquella seguridad de permanencia que tiene una persona en su trabajo u ocupación, esta también se puede entender como la duración percibida por las persona al mantener su trabajo actual sin factores externos (Marín, 2015). La estabilidad laboral no solo hace referencia a la capacidad para sostener un trabajo, sino de disfrutar de un salario estable y de una serie de beneficios por la realización de ese trabajo (Alfonzo-Guzmán, 2016).

Es deber del Estado garantizar a todos los ciudadanos colombianos el gozar de tales beneficios, tal como lo sostiene la Constitución Política (artículo 53, 1991), en donde se expone que:

El Congreso expedirá el estatuto del trabajo. La Ley correspondiente tendrá en cuenta por lo menos los siguientes principios mínimos fundamentales:

Igualdad de oportunidades para los trabajadores; remuneración mínima vital y móvil, proporcional a la cantidad y calidad de trabajo; estabilidad en el empleo; irrenunciabilidad a los beneficios mínimos establecidos en normas laborales; facultades para transigir y conciliar sobre derechos inciertos y discutibles; situación más favorable al trabajador en caso de duda en la aplicación e interpretación de las fuentes formales de derecho; primacía de la realidad sobre formalidades establecidas por los sujetos de las relaciones laborales; garantía a la seguridad social, la capacitación, el adiestramiento y el descanso necesario; protección especial a la mujer, a la maternidad y al trabajador menor de edad (Constitución Política, 1991, p. 15). 
El Estado garantiza el derecho al pago oportuno y al reajuste periódico de las pensiones legales; los convenios internacionales del trabajo debidamente ratificados, hacen parte de la legislación interna; la ley, los contratos, los acuerdos y convenios de trabajo, no pueden menoscabar la libertad, la dignidad humana ni los derechos de los trabajadores (Constitución Política, 1991, p. 15).

A partir de lo anterior, la jurisprudencia colombiana desarrolló el principio de estabilidad laboral (Duque, Quintero y González, 2016), enmarcado en la protección de los derechos de los ciudadanos con una situación de disminución física, psíquica o sensorial; por lo tanto, un trabajador con un contrato laboral no puede ser despedido de su cargo, aun existiendo causa justa, lo cual implica que en el caso del empleador llevar a cabo un despido o desvinculación mientras el trabajador posea alguno de estos fueros, estará este en el deber de reconocer las sanciones contempladas por la Ley (Duque, Quintero y González, 2016).

Ahora bien, en 1958, por primera vez un pacto internacional incluyó las necesidades de las personas discapacitadas en el Convenio sobre Discriminación (empleo y ocupación) adoptado posteriormente por la OIT (C111, 1958, art. 5). A partir de ese momento la OIT declaró medidas especiales a favor de los diversos grupos desfavorecidos, incluidas las personas con discapacidad, pero a su vez entendiendo a este último como elemento de inclusión mediada por los principios rectores de los derechos humanos, tal como expresan Araque y Suárez (2017, p. 103-104); en espera de potenciar el respeto por la libertad, igualdad y la inserción social, basándose en la no exclusión, la otredad, la vida independiente, para preservar la autonomía de la persona con discapacidad desde la igualdad y respeto por las limitaciones.

Años más tarde, la ONU (Resolución 2856, 1971) hizó la Proclamación Internacional sobre los Derechos de las Personas con Retraso Mental. Declaración que reconoció a las personas con retraso mental los mismos derechos de los demás ciudadanos.

Asimismo, las personas limitadas por aspectos neurológicos o cognitivos deben ser reconocidas en igualdad de condiciones, o de lo contrario, 
el no ser un ser considerado apto en todas sus condiciones, ser discriminado, mal tratado o estigmatizado, le genera una constante angustia estrés o presión en el momento de involucrarse en las comunidades o sociedades y limita su potencial intelectual, emocional, global (Reyes, Hernández, Chumaceiro y Salcedo, 2016, p. 64).

En ese orden de ideas, el 9 de diciembre de 1975, la ONU adoptó una declaración sobre los derechos de las personas discapacitadas (Resolución 3447, 1975), la cual contiene un compromiso internacional sobre la protección de los derechos humanos de las personas discapacitadas, los cuales son:

- Derecho al respeto de su dignidad humana.

- Derecho a disfrutar de algunos derechos civiles y políticos como otros seres humanos.

- Sus derechos a las medidas diseñadas para permitirles ser tan autosuficientes como sea posible.

- Derecho a tratamiento médico, psicológico y funcional, rehabilitación médica y social, educación, capacitación vocacional y ayuda de rehabilitación, asesoramiento, servicio de colocación y otros servicios que les permitirán desarrollar sus capacidades y habilidades para el máximo y acelerará los procesos de su integración social o reintegración.

- Derecho a la seguridad económica y social.

- Derecho a considerar sus necesidades específicas en todas las etapas de la planificación social y económica.

- Derecho a vivir con sus familias o padres adoptivos y participar en todas las actividades sociales y culturales.

- Derecho a ser protegido contra la explotación o discriminación de cualquier forma.

- Derecho a contar con asistencia letrada para la protección de sus personas y propiedades.

- Derecho de las organizaciones de personas con discapacidad a ser consultadas en asuntos de su pertinencia (Resolución $3447,1975)$. 
En Colombia, se han desarrollado diferentes planteamientos del legislador y las altas Cortes con respecto a los trabajadores que sufren algún tipo de disminución física, siendo el primer antecedente normativo la Ley 361 (1997) en la cual se establecen mecanismos de integración social de la personas con limitación; posteriormente se expide el Decreto 2463 (2001), por el cual se reglamenta la integración, financiación y funcionamiento de las Juntas de Calificación de Invalidez, integrando los diferentes niveles de pérdida de capacidad laboral, los cuales pueden ser moderados, severos o profundos, y en función a estas calificaciones se podrán hacer acreedores a una estabilidad laboral. Es menester recalcar como la estabilidad laboral actualmente cobija a trabajadores que se encuentran en situaciones puntuales como el embarazo, los padres o madres cabeza de familia, la mujeres en periodo de lactancia, los trabajadores con fuero sindical, aquellos que han sufrido un accidente laboral y los prepensionables, entre otros.

A partir de lo anterior y aún cuando en Colombia existen diversos tipos de fueros de protección al trabajador, en este artículo el análisis se centra en dos, los cuales son, el fuero del disminuido físico, psíquico y sensorial y el fuero de maternidad.

\section{El disminuido físico, psíquico y sensorial}

El termino discapacidad (como históricamente se utilizaba) se puede definir como una condición o función considerada significativamente deteriorada en relación con el estándar habitual de un individuo o grupo dentro de la sociedad. Este término es utilizado para referirse al funcionamiento individual, incluyendo el impedimento físico, el deterioro sensorial, el deterioro cognitivo, el deterioro intelectual, la enfermedad mental y varios tipos de enfermedades crónicas (Diniz, Barbosa y Rufino, 2009). El termino discapacitado, posteriormente fue prohibido por la Corte Constitucional mediante la sentencia C-458 (2015) y en su reemplazo deben usarse expresiones inclusivas, tales como, personas en situación de discapacidad o personas 
con discapacidad auditiva, etc; de esta manera la Corte acoge el lenguaje internacional que sobre esta materia se ha venido dando y pone nuestro ordenamiento a tono con los instrumentos internacionales en materia de derechos humanos.

La discapacidad se conceptualiza como una experiencia multidimensional para la persona involucrada, por poder estar afectados órganos o partes del cuerpo y estos afectar la participación de una persona en áreas de la vida (Palacios y Bariffi, 2007; Castillo y Vélez, 2001). La Clasificación Internacional del Funcionamiento, de la Discapacidad y de la Salud (CIF) de la Organización Mundial de la Salud (Resolución WHA54.21, 2001) reconoce tres dimensiones de discapacidad, los cuales están enmarcados en la estructura y función del cuerpo (deterioro del cuerpo), la actividad (restricciones de actividad) y la participación (restricciones de participación).

$\mathrm{Al}$ respecto, la sentencia C-531 (2000) desarrolla el principio constitucional de protección al discapacitado, manifestado como la efectividad del ejercicio del derecho al trabajo, condicionado al cumplimiento de los principios mínimos fundamentales establecidos en la Carta Política (artículo 53, 1991). Cuando la parte trabajadora de dicha relación está conformada por un trabajador en condición de alguna discapacidad, adquiere principal prevalencia, razón por la cual debe garantizársele permanecer en su empleo y gozar de cierta seguridad en la continuidad del vínculo laboral contraído, mientras no exista una causal justificativa del despido, teniendo como fundamento principal la protección especial de la cual forma parte. Esta seguridad de la cual se habla ha sido identificada como una "estabilidad laboral reforzada» que a la vez constituye un derecho constitucional, igualmente predicable de otros grupos sociales, como sucede con las mujeres embarazadas y los trabajadores aforados (Sentencia C-531, 2000, p. 13).

Posteriormente, por medio de la Ley Estatutaria 1618 (2013), se determina el concepto de personas en situación de discapacidad, definiéndolas como... 
... aquellas personas poseedoras de deficiencias físicas, mentales, intelectuales o sensoriales a mediano y largo plazo que, al interactuar con diversas barreras incluyendo las actitudinales, puedan impedir su participación plena y efectiva en la sociedad, en igualdad de condiciones con lo demás" (Ley Estatutaria 1618, 2013, p. 1).

Para Martínez, Uribe-Rodríguez y Velázquez-González (2014), la construcción legislativa en Colombia sobre discapacidad ha implicado grandes reflexiones y planteamientos en diferentes sectores tales como el de la educación, salud, empleo, transporte y accesibilidad, entre otros, en los cuales están implicadas las personas con discapacidad. En obligación a esto, el Estado para poder proteger los derechos de estas personas, hace uso de uno de los mecanismos existentes en Colombia para la protección de los derechos constitucionales fundamentales, la acción de tutela, cuyo fallo producto de esta acción es de inmediato cumplimiento (Constitución Política, 1991, art. 86).

Ahora bien, la Corte Suprema de Justicia en pronunciamientos contenido en la sentencia T-039 (2010), amplía el margen de cobertura la protección no sólo a las personas con discapacidades previas a la relación laboral debidamente calificadas, sino basta con solamente probar la existencia de una situación de salud que impida o dificulte sustancialmente el desempeño de sus labores en las condiciones regulares, para así poder establecer una situación de estabilidad laboral reforzada. Por otra parte, la sentencia hace un llamado al Estado en función de la Constitución (1991, art. 47) para que cumpla con su obligación de adelantar políticas de prevención, rehabilitación e integración social para los disminuidos físicos sensoriales y síquicos, con la finalidad de no dejar a estos expuestos.

En este sentido se ha establecido el derecho a la estabilidad laboral reforzada para las personas en estado de debilidad manifiesta, como una forma de protección especial y de garantía del principio de igualdad; razón que los Altos Tribunales han considerado constituye un trato discriminatorio, cuando se ha despedido de manera unilateral a una persona debido a su con- 
dición física, toda vez que no se tiene en cuenta la situación jurídica particular (Sentencia T-039, 2010).

Con el planteamiento afirmado, se concluye como basta con demostrar que la persona despedida se encuentra sometida a alguna situación de discapacidad para automáticamente ser considerado como un trato discriminatorio por parte del empleador que lo realice; y dado que tal principio es de rango constitucional, es el Estado el garante de su cumplimiento de forma inmediata, pudiendo exigir por cualquiera de los medios legales la protección del derecho fundamental.

\section{De la estabilidad laboral a la estabilidad ocupacional}

Históricamente el término utilizado para materializar el principio que protege a los trabajadores de ser despedidos con ocasión a una pérdida de capacidad laboral ha sido denominado «estabilidad laboral reforzada». Este principio, si bien es cierto, permite incluir la totalidad de las modalidades contractuales incluidas en el Código Sustantivo de Trabajo, a su vez deja por fuera otras vinculaciones comúnmente usadas por los empleadores, pero al no por cumplir estrictamente con los elementos esenciales contemplados en el mencionado código (1951, art. 23) carecían entonces de cualquier tipo de estabilidad. Así las cosas, mediante la sentencia SU-049 (2017), se unifica la jurisprudencia en el entendido de ampliar el principio de estabilidad laboral a quienes ejercen cualquier ocupación laboral, sea subordinada o no; lo cual quiere decir que el termino «estabilidad laboral reforzada" al ser un término restrictivo a los contratos laborales debía ser reemplazado por uno que incluyera también figuras como el contrato de aprendizaje y el contrato de prestación de servicios. Es por eso que la Corte Constitucional para referirse al derecho que goza todo individuo con una debilidad manifiesta, una enfermedad o situación patológica mental, de salud o física, deberá referirse al principio de "estabilidad laboral reforzada", la cual brinda un espectro más grande de protección a los contratos de prestación de trabajo. 
Con la «estabilidad laboral reforzada» se debe tener en cuenta que los contratos de prestación de servicio, y los contratos de aprendizaje están incluidos bajo el fuero reforzado y se aplica de la misma forma para los contratos de trabajo, es decir, que para el empleador poder retirar al trabajador por una condición derivada a su debilidad manifiesta, debe consultar a un gestor o inspector del Ministerio de Trabajo, quien debe verificar la justa causa de la terminación imputada, y en caso de no cumplir este formalismo, se tiene por ineficaz la desvinculación o terminación unilateral del contrato de prestación de servicio, lo cual a su vez implica una presunción de la terminación del contrato con ocasión a la condición de debilidad manifiesta, acarreando una multa de 180 Salarios Mínimos Diarios Legales Mensuales Vigentes (SMDLMV).

La Corte Constitucional ha brindado elementos para facilitar la aplicación de la "estabilidad laboral reforzada" siendo uno de estos el llamado "presunción del despido" desarrollado en la sentencia T-936 (2009), donde se afirma que de no mediar autorización del órgano competente, se presume al despido del trabajador por razones de disminución física. En ese sentido, en aquellos eventos acreditados por el juzgador como desvinculación del trabajador por haber sufrido disminución en su estado de salud sin que medie autorización del inspector de trabajo, deberá aplicar la mencionada "presunción", es decir que la desvinculación se deba a la disminución del estado de salud del trabajador (Sentencia T-936, 2009, p. 21).

Hasta este momento y en congruencia con la Ley 776 (2002), existe una limitante al momento de aplicar la «estabilidad reforzada", la cual consiste en la necesidad calificar el estado de capacidad laboral del trabajador (sobre la disminución que origina la estabilidad) previo a la vinculación a la empresa, situación que facilita a los empleadores la desvinculación, por este motivo, y a fin de delimitar esta capacidad de dejar desprotegidos a sus trabajadores de la disminución física, psíquica y sensorial, la Corte Constitucional mediante la sentencia T-198 (2006) extendió la protección no solo a las trabajadores previamente calificados si- 
no también a todos aquellos que prueben que poseen condiciones de salud que impidan o dificulten el desempeño regular de sus labores (Sentencia T-198, 2006, p. 33).

De igual forma, en su artículo 13, la Constitución Política (1991) expone la libertad y los mismos derechos y oportunidades para todos los sujetos, por ende, todos los ciudadanos colombianos deben obtener el mismo respeto, garantía, promoción y protección de sus derechos sin ningún tipo de discriminación racial, religiosa, filosófica, política, etc. (Constitución Política, 1991, art. 13). Bajo esta premisa es necesaria la evaluación de la condición en que se encuentra el sujeto para así poder determinar si es necesario proceder a la acción de tutela como un mecanismo transitorio para proteger los derechos constitucionales del mismo.

Ahora bien, el planteamiento desarrollado por la Corte y posteriormente por los doctrinantes en la teoría de los riesgos, bien sean de origen común o profesional, son entendibles per se; así de esta forma, el trato hacia las personas que por riesgo propio adquieren una discapacidad o enfermedad, es decir, bajo su propio riesgo, no puede ser el mismo que el de aquellas al ingresar en plenitud de condiciones al mercado laboral y posteriormente, por un riesgo no atribuible directamente a ellos, sino al empleador, sufren una disminución en su capacidad laboral. De ahí la importancia que tiene para los dictámenes de perdida de la capacidad laboral emitidos por los departamentos de Medicina Laboral, así como de aquellos emitidos por las Juntas de Calificación de Invalidez sea indispensable que contengan primordialmente porcentaje, fecha de estructuración y sobre todo el origen de las patologías, para en primera instancia se sepa cual de las entidades es la encargada de asumir el riesgo sufrido por el trabajador discapacitado.

En efecto, según la Sentencia T-780 (2008), un acontecimiento que pone a un sujeto ante una situación de debilidad manifiesta es aquel que le sucede a un trabajador cuando en cumplimiento de su labor sufre un accidente de trabajo, y por ende, ante sus afectaciones de índole físico se ubica en una condición especial. Condición que el Estado colombiano favorece al encajar en una 
situación de debilidad manifiesta respecto de su empleador (Sentencia T-780, 2008, p. 8).

Finalmente, y acorde a lo manifestado en la sentencia T-320 (2016), para la existencia de "estabilidad laboral reforzada», no son necesarias patologías calificadas de origen laboral ni ser formalmente declaradas (dictamen), o cuantificada por una junta de calificación. Lo anterior implica a la mencionada estabilidad operar tanto para patologías tratadas de origen común como para aquellas patologías originadas de una accidente de trabajo o enfermad profesional. El argumento central se basa en catalogar la "estabilidad laboral reforzada" como un derecho de todas las personas que por el deterioro de su salud están en una situación de debilidad manifiesta, lo cual significa que cuando la condición de salud se ve afectada no es necesario contar con una discapacidad declarada, certificada y cuantificada por una junta de calificación médica, ni con un origen determinado.

\section{Protección laboral reforzada de la mujer embarazada}

La estabilidad reforzada de las mujeres embarazadas ha sido objeto de estudio por parte de los Altos Tribunales desde el inicio de estos, teniendo entre los principales motivos de este estudio lo sensible de los sujetos implicados. Por una parte se encuentran las mujeres en estado de embarazo lo que per se representa un fuero, pero también se tiene como sujeto de protección la vida del menor que viene en camino. Se evidencia una tensión entre el principio de libertad o autonomía contractual propio de los empleadores frente a los derechos fundamentales posiblemente vulnerados de la mujer embarazada y al menor que se encuentra en gestación.

La Corte ha protegido todas las modalidades de alternativa laboral, como son los contratos a término indefinido, a término fijo, por obra o labor contratada y luego de la sentencia SU-049 (2017) opera incluso para los contratos de prestación de servicios, aunque las medidas de protección son viables dependiendo de cada caso (Sentencia SU-070, 2013). 
La protección que se ha dado por la Corte en estos casos, va desde el pago de gastos ocasionados por la maternidad en eventos donde se haya despedido hasta la indemnización (Código Sustantivo del Trabajo, 1951, art. 64), pasando por el pago de los salarios y prestaciones dejadas de percibir e incluso en algunos casos el reintegro de la trabajadora despedida; sin embargo podría pensarse que las medidas de protección para estos casos no han sido acordes al criterio de razonabilidad de las cargas impuestas a los empleadores en virtud del principio de solidaridad, proporcionalidad y razonabilidad.

Lo anterior, motivado por la sentencia en mención, la cual expuso como la estabilidad laboral de la mujer en estado de embarazo se debe proteger independientemente del tipo de contratación, sin importar si el empleador conoce el estado de gravidez, lo cual únicamente incide en la definición del tipo de protección a otorgar para la misma, ya sea pago de seguridad social, pago de salarios o factores salariales e inclusive el pago de sanciones (Sentencia SU-070, 2013).

Hasta este momento, la notificación del embarazo es un elemento fundamental al momento de medir el alcance de la protección, pero aun cuando esta notificación no exista, el empleador esta obligado en el mejor de los casos al pago de seguridad social de la trabajadora embarazada, lo cual parece injusto en el entendido de no tener conocimiento por parte del empleador quien obra de buena fe. Por lo anterior, la Corte en la sentencia SU-075 (2018) afirma que el empleador no puede estar en la obligación de estar pendiente de la situación de salud de su trabajadora, al no tener forma de conocer la intimidad de la historia clínica de las personas contratadas, porque de ser así se generaría una congestión y una ocupación adicional a las labores de la empresa en cosas diferentes a su objeto social. Por esta razón, la Corte aclara que la carga de demostrar el embarazo corresponde a la mujer embarazada, quien debe notificar por los medios legales pertinentes al empleador, quien no podrá saber el momento del estado de debilidad manifiesta con origen del embarazo. 


\section{Levantamiento de la estabilidad}

En la sentencia T-003 (2010) de la Corte Constitucional se da claridad al procedimiento, al surtir por parte de los empleadores la posibilidad de dar por terminado el contrato a quienes se encuentren en estabilidad reforzada por razones de salud, siendo lo primero el requerir la autorización previa del Ministerio de Trabajo, lo cual cierra la puerta a lo que comúnmente se realizaba, al indemnizar a los trabajadores incursos en un estado de estabilidad ocupacional, legalizando de esta manera la terminación del vínculo. El Alto Tribunal ha sostenido que el despido realizado con el trabajador en estado de debilidad, se debe tornar ineficaz, a menos que el empleador demuestre previamente ante el Ministerio de Trabajo la terminación por motivos diferentes a su condición física o psíquica o sensorial en particular, cumpliendo así con lo desarrollado por la Ley 361 (1997), la cual estableció los mecanismos de integración laboral a favor de las personas con discapacidad (Sentencia T-003, 2010, p. 13).

El artículo 26 (Ley 361, 1997), consagra la no discriminación de las personas en situación de discapacidad, beneficio desarrollado no solo a los trabajadores en situación de discapacidad como tal, sino también a aquellos trabajadores que sufren deterioros de salud en el desarrollo de sus funciones laborales (Ley 361, 1997, p. 6). A continuación, se expone lo consagrado en el artículo en mención:

Artículo $26^{\circ}$.- Modificado por el art. 137, Decreto Nacional 019 de 2012. En ningún caso la limitación de una persona, podrá ser motivo para obstaculizar una vinculación laboral, a menos que dicha limitación sea claramente demostrada como incompatible e insuperable en el cargo que se va a desempeñar. Así mismo, ninguna persona limitada podrá ser despedida o su contrato terminado por razón de su limitación, salvo que medie autorización de la oficina de Trabajo (Ley 361. 1997, p. 6). 
No obstante, quienes fueren despedidos o su contrato terminado por razón de su limitación, sin el cumplimiento del requisito previsto en el inciso anterior, tendrán derecho a una indemnización equivalente a ciento ochenta días del salario, sin perjuicio de las demás prestaciones e indemnizaciones a que hubiere lugar de acuerdo con el Código Sustantivo del Trabajo y demás normas que lo modifiquen, adicionen, complementen o aclaren (Ley 361, 1997, p. 6).

Así mismo, la sentencia T-642 (2010) establece la concordancia de la aplicación de la estabilidad ocupacional reforzada y la normatividad colombiana, por la cual, los trabajadores con una posición de debilidad manifiesta, a partir del quebranto de su salud poseen todo el derecho a continuar en su sitio de trabajo hasta cuando se configure una causal que valga la desvinculación de índole laboral, la cual debe ser preliminarmente constatada por un inspector de trabajo o autoridad acreditándola (Sentencia T-642, 2010). Por tal motivo, si se logra determinar como motivos del despido de un sujeto el encontrarse con su salud afectada o se realiza sin la aprobación de la autoridad competente, se establece como causante de la desvinculación laboral a la circunstancia de debilidad e indefensión del trabajador, vulnerando en gran medida sus derechos fundamentales. Concediendo así por parte del juzgador el amparo invocado y declaración de la ineficacia del despido y por ende ordenando su reintegro a un cargo acorde con su situación especial (Sentencia T-642, 2010, p. 12).

\section{Conclusiones}

La estabilidad laboral reforzada es un mecanismo implementado con el objetivo de ofrecer protección laboral a aquellas personas con una condición especial que los impide estar al 100\% de sus condiciones, o en su defecto, la misma condición hace que estén en riesgo permanente de ser despedidos.

El término estabilidad laboral, es restrictivo a las personas vinculadas mediante contratos de trabajo exclusivamente y deja por fuera vinculaciones como los contrato de prestación de servicios, así como a los contratos de aprendizaje, razón por la cual, 
la Corte Constitucional con la intención de ampliar la cobertura implementa por medio de la sentencia SU-049 (2017) el término «estabilidad ocupacional» donde se incluyen todas las personas que ejercen algún tipo de labor, sea subordinada o no.

El concepto de discapacidad se aplica en una persona con una condición o función considerada significativamente deteriorada en relación con el estándar habitual de un individuo; este deterioro puede darse a nivel físico, sensorial, cognitivo o intelectual, entre otros. De igual forma, el término discapacitado fue posteriormente prohibido por la Corte por considerarlo discriminatorio y en su reemplazo se debe hablar de personas en condición de discapacidad, o en su defecto especificar qué tipo de disminución la afectó.

La mujer en estado de embarazo así como aquella en periodo de lactancia es protegida constitucional y jurisprudencialmente independientemente de la modalidad o alternativa laboral por la cual se vincule, como lo es el contrato a término indefinido, a término fijo, por obra o labor contratada, acorde a lo estipulado en la sentencia SU-070 (2013). Para que la estabilidad ocupacional reforzada empiece a operar es necesario que la mujer cumpla con los requisitos establecidos en la sentencia SU-075 (2018). Finalmente vale recalcar como en función a los últimos pronunciamientos de la Corte Constitucional la protección especial se hace extensiva las embarazadas vinculadas mediante contrato de prestación de servicios (Sentencia SU-049, 2017).

La estabilidad ocupacional reforzada es una garantía real de la cual disponen los trabajadores para no ser despedidos con motivo a la disminución de pérdidas de capacidad laboral u ocupacional. El incumplimiento por parte de los empleadores a estos lineamientos de la protección, implican que al desvincular algún trabajador con motivo su estado de salud, pueden hacerse acreedores a sanciones previstas en la ley, las cuales variaran dependiendo al tipo de fuero del trabajador para cada caso en particular y van desde dejar sin efecto las terminaciones de contrato del trabajador con el fuero hasta el pago de indemnizaciones económicas. 


\section{Referencias}

Alfonzo-Guzmán, R. (2016). Nueva didáctica del derecho del trabajo (16 ${ }^{\mathrm{a}}$ ed.). Caracas: Ediciones Paredes.

ANDI. (2017). Salud y estabilidad en el empleo: retos jurídicos y económicos para la sostenibilidad de las empresas. Medellín: Mundo Libro. Recuperado de http://www.andi.com. co/Uploads/ANDI\%20-\%20Salud\%20y\%20estabilidad\%20 en\%20el\%20empleo.pdf

Araque, F. y Suárez, O. (2017). Reflexiones teóricas y legales del adulto mayor y la discapacidad en Colombia. Revista Jurídicas CUC, 13(1), 97-120. http://dx.doi.org/10.17981/ juridcuc.13.1.2017.5

Asamblea General de las Naciones Unidas. (1983). Ejecución del Programa de Acción Mundial para los Impedidos. [A/RES/38/28]. Recuperado de https://undocs.org/es/A/ $\mathrm{RES} / 38 / 28$

Asamblea General de las Naciones Unidas. (1975). Declaración de los Derechos de los Impedidos. [A/RES/34/47(XXX)]. Recuperado de https://undocs.org/es/A/RES/3447(XXX)

Asamblea General de las Naciones Unidas. (1971). Declaración de los derechos del retrasado mental. [A/RES/2856(XXVI)]. Recuperado de https://undocs.org/es/A/RES/2856(XXVI)

Asamblea General de las Naciones Unidas. (1948). Declaración Universal de Derechos Humanos. [Resolución 217 A (III)]. Recuperado de https://undocs.org/es/A/RES/217(III)

Castillo, J. y Vélez, C. (2001). Salud pública y discapacidad: Una mirada alternativa. Ánfora, 9(16). 75-86. https://doi. org/10.30854/anf.v9.n16.2000.283

Diniz, D., Barbosa, L y Rufino, W. (2009). Discapacidad, Derechos Humanos y Justicia. Revista Internacional de Derechos Humanos, 6 (11), 65-77.

Duque, S., Quintero, M y González, P. (2016). Sobre la protección en el trabajo para las personas con discapacidad. Revista de Derecho, 45, 59-84. 
Marín, F. (2015). La estabilidad laboral: aspectos y procedimientos en la LOTTT. Cuestiones Jurídicas, 9(2), 11-27.

Martínez, A., Uribe-Rodríguez, A y Velázquez-González, H. (2015). La discapacidad y su estado actual en la legislación colombiana. Revista Duazary, 12(1), 49-58. http://dx.doi. org/10.21676/2389783X.1398

OIT. (1983). Convenio sobre la readaptación profesional y el empleo (personas inválidas). [C159]. Recuperado de https:// www.ilo.org/dyn/normlex/es/f?p=NORMLEXPUB:12100:0 ::NO::P12100_INSTRUMENT_ID:312304

OIT. (1983). Recomendación sobre sobre la readaptación profesional y el empleo (personas inválidas). [R168]. Recuperado de https://www.ilo.org/dyn/normlex/es/f?p=NORMLEXPU B:12100:::NO:12100:P12100_ILO_CODE:R168:NO

OIT. (1958). Convenio sobre discriminación (empleo y ocupación). [C111]. Recuperado de https://www.ilo.org/dyn/normlex/es/f?p=NORMLEXPUB:12100:0::NO::P12100_ILO_ CODE:C111

OMS. (2001). Clasificación Internacional del Funcionamiento, de la Discapacidad y de la Salud (CIF). [WHA54.21]. Recuperado de http://www.who.int/classifications/icf/wha-sp. pdf?ua $=1$

Palacios, A. y Bariffi, F. (2007). La discapacidad como una cuestión de derechos humanos Una aproximación a la Convención Internacional sobre los Derechos de las Personas con Discapacidad. Madrid: Ediciones Cinca.

República de Colombia. Asamblea Nacional Constituyente. (1991). Constitución Política de Colombia. [Const]. Recuperado de http://wsp.presidencia.gov.co/Normativa/Documents/Constitucion-Politica-Colombia.pdf

República de Colombia. Congreso de la Republica. (7 de febrero de 1997). Por la cual se establecen mecanismos de integración social de las personas con limitación <en situación de discapacidad $>$ y se dictan otras disposiciones. [Ley 361]. DO: 42.978 . 
República de Colombia. Congreso de la Republica. (20 de noviembre de 2001). Por el cual se reglamenta la integración, financiación y funcionamiento de las juntas de calificación de invalidez. [Decreto 2463]. DO: 44.622.

República de Colombia. Congreso de la Republica. (17 de diciembre de 2002). Por la cual se dictan normas sobre la organización, administración y prestaciones del Sistema General de Riesgos Profesionales. [Ley 776]. DO: 45.037.

República de Colombia. Congreso de la Republica. (27 de febrero de 2013). Por medio de la cual se establecen las disposiciones para garantizar el pleno ejercicio de los derechos de las personas con discapacidad. [Ley Estatutaria 1618]. DO: 48.717.

República de Colombia. (1951). Código Sustantivo del Trabajo. [Art. 23]. DO. 27622.

República de Colombia. Corte Constitucional. (24 de julio de 2018). Sentencia SU-075. T-6.240.380, T-6.318.375 y T-6.645.503 [MP Gloria Stella Ortiz Delgado].

República de Colombia. Corte Constitucional. (2 de febrero de 2017). Sentencia SU-049. Exp. T-4632398. [MP María Victoria Calle Correa].

República de Colombia. Corte Constitucional. (21 de junio de 2016). Sentencia T-320. Exp. T-5.187.233 [MP Alberto Rojas Rios].

República de Colombia. Corte Constitucional. Sala Plena. (22 de julio del 2015). Sentencia C-458. Exp. D-10585. [MP Gloria Stella Ortiz Delgado].

República de Colombia. Corte Constitucional. Sala Plena. (13 de febrero del 2013). Sentencia SU-070. Exp. T-2.361.117. [MP María Victoria Calle Correa].

República de Colombia. Corte Constitucional. Sala Plena. (19 de agosto del 2010). Sentencia T-642. Exp. T-2538928. [MP Luis Ernesto Vargas Silva]. 
República de Colombia. Corte Constitucional. Sala Plena. (1 de febrero del 2010). Sentencia T-039. Exp. T-2396452. [MP Jorge Iván Palacio Palacio].

República de Colombia. Corte Constitucional. Sala Plena. (14 de enero del 2010). Sentencia T-003. Exp. T-2.193.962. [MP Jorge Ignacio Pretelt Chaljub].

República de Colombia. Corte Constitucional. Sala Plena. (14 de diciembre del 2009). Sentencia T-936. Exp. T-2.326.074, T- 2.384.577 y T-2.387.690. [MP Humberto Antonio Sierra Porto].

República de Colombia. Corte Constitucional. Sala Plena. (13 de agosto del 2008). Sentencia T-780. Exp. T-1877545. [MP Marco Gerardo Monroy Cabra].

República de Colombia. Corte Constitucional. Sala Plena. (16 de marzo del 2006). Sentencia T-198. Exp. 1134873. [MP Marco Gerardo Monroy Cabra].

República de Colombia. Corte Constitucional. Sala Plena. (10 de mayo del 2000). Sentencia C-531. Exp. D-2600. [MP Álvaro Tafur Galvis].

Reyes, I., Hernández, J., Chumaceiro, A. y Cadrazco, C. (2016). Epilepsia un abordaje social: experiencia de sensibilización y concientización ciudadana. ORBIS Revista Científca Electrónica de Ciencias Humanas. Scientific e-journal of Human Sciences, 35(12), 58-76.

Rojas, C. (2016). La flexibilización laboral en Colombia. Jurídicas CUC, 12(1), 17-29. http://dx.doi.org/10.17981/juridcuc.12.1.2016.2

UNESCO. (1981). Conferencia Mundial sobre las acciones y estrategias para la educación, prevención e integración de las personas impedidas. Declaración SundBerg. Torremolimos, España. 
Darwin Eliecer Solano Bent es Doctorando en Derecho de la Universidad del Norte (Colombia). Magíster en Derecho y Especialista en Derecho Laboral. Abogado y Docente de Derecho Laboral. Investigador del Grupo de investigación Derecho, Política y Sociedad de la Universidad de la Costa (Colombia). 